\title{
Delays in Carotid Endarterectomy: The Process is the Problem
}

\author{
Dylan Blacquiere, Michael Sharma, Prasad Jetty
}

\begin{abstract}
Background: Current recommendations for carotid endarterectomy (CEA) for symptomatic carotid stenosis state benefit is greatest when performed within two weeks of symptoms. However, only a minority of cases are operated on within this guideline, and no systematic examinations of reasons for these delays exist. Methods: All CEA cases performed at our institution by vascular surgery for symptomatic carotid stenosis after neurologist referral in 2008-2009 were reviewed. Dates of symptom onset, initial presentation, referral to and evaluation by neurology and vascular surgery, vascular imaging, and CEA were collected, and the length of time between each analysed. Reasons for delays were noted where available. Results: Of 36 included patients, 34 had CEA more than two weeks after symptom onset. Median time to CEA from onset was 76 days (IQR, 38-105 days). Longest intervals were between surgeon assessment and CEA (14 days; IQR, 9-21 days), neurology referral and neurologist assessment (9 days; IQR, 2-26 days), vascular imaging and referral to vascular surgery (9 days; IQR, 2-35 days) and vascular surgery referral and assessment (8 days; IQR, 6-15 days). Few patients $(44.1 \%)$ had reasons for delays identified; of these, process-related delays were related to delayed vascular imaging, delayed referral by primary care physicians, or multiple conflicting referrals. Conclusions: There are significant delays between symptom onset and CEA in patients referred for CEA, with delay highest between specialist referral and evaluation. Strategies to reduce these delays may be effective in increasing the proportion of procedures performed within two weeks of symptom onset.
\end{abstract}

RÉSUMÉ: Retards à effectuer l'endartérectomie carotidienne : le problème réside dans le processus. Contexte : Selon les recommandations actuelles pour l'endartérectomie carotidienne (EC) effectuée pour une sténose carotidienne symptomatique, on obtient les meilleurs résultats lorsque l'intervention est effectuée dans les deux semaines suivant l'apparition des symptômes. Cependant, seulement une minorité de patients sont opérés dans le délai recommandé par les lignes directrices et aucun examen systématique des raisons du délai n'a été effectué. Méthode : Nous avons revu les dossiers de tous les cas d'EC référés par un neurologue, qui ont subi une chirurgie vasculaire dans notre institution pour une sténose carotidienne symptomatique en 2008-2009. Les dates de début des symptômes, de la consultation initiale, de la demande de consultation en spécialité et de l'évaluation en neurologie et en chirurgie vasculaire, de l'imagerie vasculaire et de l'EC ont été colligées et le temps écoulé entre chacune de ces dates a été analysé. Les raisons expliquant les délais ont été notées quand elles étaient disponibles. Résultats : Parmi les 36 patients inclus dans l'étude, 34 ont subi une EC plus de deux semaines après le début des symptômes. Le temps médian écoulé entre le début des symptômes et l'EC était de 76 jours (écart interquartile (ÉIQ) 38-105 jours). Les intervalles les plus longs étaient entre l'évaluation par le chirurgien et l'EC (14 jours; ÉIQ 9-21), la demande de consultation en neurologie et l'évaluation par le neurologue (9 jours; ÉIQ 2-26 jours), l'imagerie vasculaire et la demande de consultation en chirurgie vasculaire (9 jours; ÉIQ 2-35 jours) et la demande de consultation en chirurgie vasculaire et l'évaluation par le chirurgien (8 jours; ÉIQ 6-15 jours). Les raisons des délais étaient identifiées chez moins de la moitié des patients $(44,1 \%)$; parmi eux, des délais dans le processus étaient reliés à l'imagerie vasculaire, à la demande de consultation par le médecin de première ligne ou à plusieurs demandes de consultation conflictuelles. Conclusions : Il existe des délais significatifs entre le début des symptômes et l'EC chez les patients référés pour une EC et le délai le plus long se situe entre la demande de consultation au spécialiste et l'évaluation faite par celui-ci. Des stratégies pour diminuer ces délais seraient susceptibles d'augmenter la proportion d'interventions effectuées dans les deux semaines suivant le début des symptômes.

Can J Neurol Sci. 2013; 40: 585-589

\section{INTRODUCTION}

Patients who have a transient ischemic attack (TIA) or minor stroke are at high risk of recurrent stroke, with risks of as high as $12 \%$ within one week of the inciting event ${ }^{1-3}$ Carotid endarterectomy (CEA) for symptomatic stenosis is one of the most effective interventions in neurology, with an NNT of 3 for stenosis greater than $70 \%$ and an NNT of 6 for stenosis between 50 and $70 \%$ when the procedure is performed within two weeks of a TIA or minor stroke, ${ }^{4-8}$. Canadian and international guidelines recommend surgery within this timeframe for maximal benefit. Diagnosis, assessment of etiology and management in this setting requires coordination between multiple physicians; however, in the absence of a welldeveloped process, these steps may result in substantial delay to surgery, minimizing its beneficial effect.
A recent survey of 139 patients receiving CEA after TIA found a median time between symptom onset and CEA of 26 days ${ }^{9}$. These times were shortened in hospitalized inpatients and in those receiving care via the emergency room, but the time to surgery still exceeded the two weeks recommended by

\footnotetext{
From the Department of Medicine, Division of Neurology (DB), Department of Surgery, Division of Vascular and Endovascular Surgery (PJ), The Ottawa Hospital, and the University of Ottawa, Ottawa; Department of Medicine, Division of Neurology (MS), McMaster University and the Population Health Research Institute, Hamilton, Ontario, Canada.

Received November 22, 2012. Final Revisions Submitted February 25, 2013. Correspondence to: Dylan Blacquiere, Department of Medicine, Division of Neurology, The Ottawa Hospital, and the University of Ottawa, Civic Campus, 1053 Carling Avenue, Ottawa, Ontario, K1Z 5R7, Canada. Email: dblacquiere@toh.on.ca.
} 
guidelines ${ }^{8}$. Other surveys have found similar or longer waiting times ${ }^{10,11}$, and noted that delays to surgery were associated with an increase in the number of cerebrovascular events prior to intervention, many of which are disabling or fatal ${ }^{9,12}$. Patients undergoing evaluation as outpatients were less likely than inpatients to receive CEA in a timely fashion ${ }^{13}$. In a Canadian cohort of patients with TIA or minor stroke due to carotid artery disease, only $8 \%$ of symptomatic patients received CEA within two weeks ${ }^{14}$. Reasons for delay included retinal presentation of symptoms, referral from an outpatient source, and distance from the tertiary institution ${ }^{14}$. One factor cited as a means to decrease delay to CEA is emergent evaluation by a neurologist or stroke prevention clinic to streamline referral to surgery ${ }^{11,15}$. However, a recent survey at our institution found the inverse; that referral and evaluation by a neurologist led to a paradoxical increase in time from symptom onset to surgery ${ }^{14}$. This finding requires further examination to determine what the potential reasons for this increase in wait times may be, and what interventions may be appropriate in order to minimize these delays. A detailed examination of the reasons for delay to CEA is needed in order to identify targets for system improvement.

This retrospective study is designed to examine the reasons for delay between symptom onset and CEA in patients referred to a vascular surgery service after being evaluated by a neurologist. We hypothesize that identification of these reasons will present opportunities for system change to ensure timely CEA for patients with symptomatic carotid disease.

\section{METHODS}

We conducted a retrospective cohort study on a subgroup of our previously published cohort ${ }^{9}$. Briefly, patients who experienced symptoms of TIA or minor stroke were seen by a primary health care provider (family physician or emergency room physician) who referred the patient to a neurologist for an assessment of symptoms. In most cases, these patients were referred to the stroke prevention clinic at our institution, where patients with cerebral ischemia can be rapidly triaged and referred for appropriate testing and therapy, including CEA. Patients not referred to the stroke prevention clinic were instead assessed by a general neurologist, either at our institution or in the community. All patients were then referred to the vascular surgery department, and are placed in a single referral queue based on priority. Patients were not referred to a specific vascular surgeon, but the same vascular surgeon who was assigned the consult performed both consultation and surgery. All vascular surgeons in our hospital's catchment area participate in this system, which provides over $90 \%$ of carotid revascularization procedures in our centre. The remainder are performed by neurosurgeons or are carotid stenting procedures performed by interventional neuroradiologists. These could not be reliably captured in our study, but comprise less than $10 \%$ of carotid procedures at our institution.

The charts and electronic health records of all individuals with TIA or minor stroke who had a CEA performed by the vascular surgery service at our institution for the calendar years 2008-2009 and who had been recorded as being referred from a neurologist were examined for the source of referral $(n=42)$. We included those patients with a documented referral note from a neurologist, or those whose neurologic referral source was noted

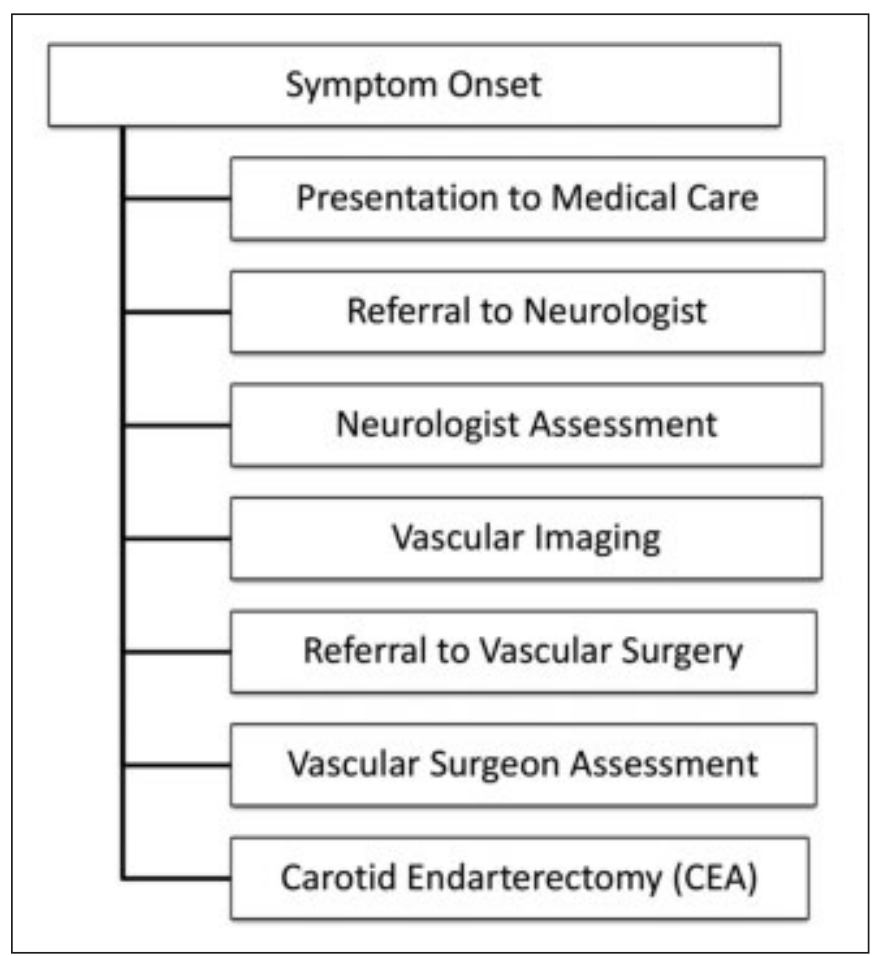

Figure 1: Clinical milestones in the evaluation and referral process for carotid endarterectomy.

elsewhere, such as in physician's orders, consultation sheets or progress notes. Patients were excluded if CEA was performed with no documented referral from a neurologist, and if surgery was performed for asymptomatic carotid stenosis (defined as patients with symptoms not referable to a vascular territory at risk from documented carotid stenosis, or as patients with symptoms that were not vascular in nature).

\section{Data Collection and Milestones}

We used a standardised data form for extraction and obtained demographic information and clinical characteristics of the presenting event from each chart. Clinical milestones, defined as the date of a) symptom onset, b) initial presentation to a physician, c) referral to a neurologist by primary care physician, d) assessment by a neurologist, e) cerebrovascular imaging, f) referral to a vascular surgeon for consideration of CEA, g) assessment by a vascular surgeon, and h) CEA, were noted, and the number of days between each milestone were recorded (Figure 1). In cases where one milestone occurred earlier than the one preceding it in this schema, such as vascular imaging preceding neurology assessment, a time of zero days was recorded for statistical purposes. Charts were reviewed in detail to determine a reason for the time between milestones and were recorded if present. The median time and interquartile range (IQR) between each milestone were calculated. Outliers in each case (defined as clear deviations from normal clinical course for unavoidable reasons, such as delayed surgical assessment due to intervening hospitalization or previous carotid Doppler screening for asymptomatic disease) were excluded. 


\section{RESULTS}

Records were obtained for 42 patients, of whom 36 were eligible for inclusion (Table 1). Most patients were male (52.8\%) with a median age of 70 years, and most patients (75.0\%) lived within $30 \mathrm{~km}$ of the tertiary care hospital. Five patients $(13.9 \%)$ were referred to vascular surgery as inpatients. Two (5.6\%) had CEA within two weeks of ischemic symptoms as recommended by guidelines. Both of these patients were admitted to hospital after their stroke and transferred directly to vascular surgery. Most $(75.0 \%)$ were evaluated by carotid Doppler to determine the degree of stenosis. Most patients $(72.8 \%)$ had between 70 $99 \%$ stenosis of the ipsilateral carotid artery.

\section{Evaluation Milestones}

The longest intervals between milestones were those between vascular surgeon assessment and CEA (14 days; IQR, 9-21 days), referral to neurology and neurologist assessment (9 days; IQR, 2-26 days), vascular imaging following neurologist assessment and referral to vascular surgery (9 days; IQR, 2-35 days) and referral to vascular surgery and vascular surgeon assessment (8 days; IQR, 6-15 days) (Figure 2). In contrast, there was minimal time between symptom onset and presentation to medical care (0 days; IQR, $0-0$ days), presentation and referral to a neurologist (0 days; IQR, 0-0 days), and neurologist evaluation and vascular imaging (0 days, IQR: 0-2 days). Overall, median time to CEA from symptom onset was 76 days (IQR, 38-105 days). In $22.2 \%$ of cases, vascular imaging preceded assessment by neurologists; the time between these milestones was set at 0 days for these cases for statistical purposes.

Table 1: Patient screening and characteristics

\begin{tabular}{ll} 
Characteristic & Number of Patients \\
Patients Screened & 42 \\
No documented neurology referral & 5 \\
Asymptomatic carotid stenosis & 1 \\
Eligible Patients & 36 \\
Median Age & 70 \\
Female & $17(47.2 \%)$ \\
Inpatient referral & $5(13.9 \%)$ \\
Surgery within 2 weeks & $2(5.6 \%)$ \\
Initial vascular investigation & \\
Carotid Doppler & $27(75.0 \%)$ \\
CTA & $5(13.9 \%)$ \\
MRI/MRA & $4(11.1 \%)$ \\
Degree of Stenosis & \\
$50-69 \%$ & $5(13.9 \%)$ \\
$70-99 \%$ & $26(72.2 \%)$ \\
Unknown & $5(13.9 \%)$ \\
Distance from Hospital & \\
$<10 \mathrm{~km}$ & $17(47.2 \%)$ \\
$10-30 \mathrm{~km}$ & $10(27.8 \%)$ \\
$30-100 \mathrm{~km}$ & $8(22.2 \%)$ \\
$>100 \mathrm{~km}$ & $1(2.8 \%)$ \\
\hline
\end{tabular}

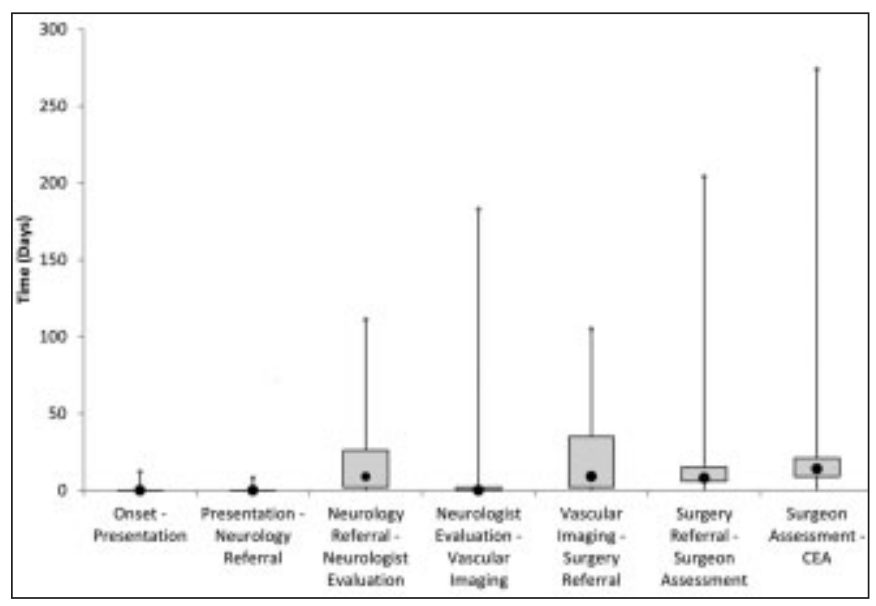

Figure 2: Median time between each clinical milestone. Points represent median time to milestone; boxes represent IQR; lines represent the maximum time interval for each milestone.

\section{Accumulated Time Modelling}

Times between each milestone were added cumulatively in order to model the length of time that could be anticipated if an individual experienced the time interval between each milestone. The median time, as well as the times representing the first and third quartile intervals between each milestone, were added in separate models. A patient who experienced the median time interval between each milestone would wait 40 days between onset of symptoms and CEA; a patient experiencing the first quartile time interval between each milestone would wait 19 days between symptoms and CEA, while 99 days would elapse for a patient waiting the third quartile time interval between these milestones (Figure 3).

\section{Reasons for Delay in Surgery}

Of the 36 patients who had been referred by a neurologist to a vascular surgeon, $34(94.4 \%)$ had surgery outside of the recommended two week interval after onset of symptoms. Of these, 15 patients $(44.1 \%)$ had a reason for the delay to surgery noted in the chart or EHR (Table 2). Common reasons for delays included neurologist uncertainty regarding the initial diagnosis (20.0\%), completed stroke deemed unsafe for intervention $(13.3 \%)$, other medical complications such as myocardial infarction (MI) (13.3\%), or initial refusal of surgery by the patient (13.3\%). However, 33.3\%of documented delays were for process issues as opposed to patient factors. These included delayed vascular imaging, delayed referral by primary care physicians, or multiple conflicting referrals causing scheduling errors.

\section{DISCUSSION}

In this retrospective study, few patients who underwent CEA for carotid stenosis after neurologist assessment for TIA or minor stroke received therapy within two weeks from symptoms in accordance with suggested guidelines. Our median time (73 days) between symptom onset and CEA in our cohort of patients referred to vascular surgery from a neurologist was larger than 
the median time (26 days) in a group of all patients referred in a previously studied cohort ${ }^{8}$. We also determined the specific delays for each event in the evaluation process. The largest time intervals occurred between surgical assessment and CEA, but large intervals also occurred between completion of vascular imaging after neurology assessment and referral to a vascular surgeon, and between referral and assessment by both neurology and vascular surgery. About half of patients had a documented reason for delay. Though many of these were for medical reasons or due to patient issues, the remainder were associated with process issues, which present targets for system improvement, particularly for neurologists who are referred patients with symptomatic carotid stenosis. In addition, there was a high degree of variability in time intervals for individual patients. This suggests that there may not be an inherent reason for delay in surgery, and instead points to issues with the process itself as the cause for high intervals between clinical milestones. Both patients who received surgery in the recommended time frame were admitted after their strokes, reflecting patterns seen in other studies $^{13}$.

As shown in Figure 3, increasing time intervals may accumulate quickly; each milestone may add increasing time and result in rapid inability to meet the guideline of surgery within two weeks of symptoms. Though these represent idealized scenarios and not actual clinical cases, it is not difficult to see that relatively small intervals can lead to a progressively larger time between symptom onset and surgery. This underscores the importance of addressing each timepoint as an opportunity to effect systemic change. It should not be taken as a recommendation to eliminate any of these steps, particularly the need for neurologist involvement, as in many cases the expertise of the neurologist was needed to determine the diagnosis, the need for surgery, and the overall clinical status of the patient. Rather, the possibility of delays occurring as a result of neurologist consultation should be recognized, and stroke system development should be tailored to minimize possible delays that occur from this, or any other, interval between milestones. The reasons for delay attributable to process included delayed or cancelled referral from primary care physicians, or delays in obtaining cerebrovascular or cardiac imaging prior to surgery.

\section{Table 2: Documented reasons for surgical delay $(n=15)$}

\begin{tabular}{lc}
\hline Delay Rationale & Patients (n=15) \\
$\begin{array}{l}\text { Nonspecific symptoms/clinical } \\
\text { uncertainty }\end{array}$ & $3(20.0 \%)$ \\
$\begin{array}{l}\text { Surgery delayed by completed stroke } \\
\text { Surgery delayed by other medical } \\
\text { complication }\end{array}$ & $2(13.3 \%)$ \\
Surgery initially refused by patient & $2(13.3 \%)$ \\
Initial referral by GP cancelled or delayed & $2(13.3 \%)$ \\
$\begin{array}{l}\text { Delayed imaging } \\
\text { Prolonged presurgical evaluation due to } \\
\text { medical complexity }\end{array}$ & $2(13.3 \%)$ \\
$\begin{array}{l}\text { Multiple surgical services evaluating } \\
\text { patient }\end{array}$ & $1(13.3 \%)$ \\
\hline
\end{tabular}

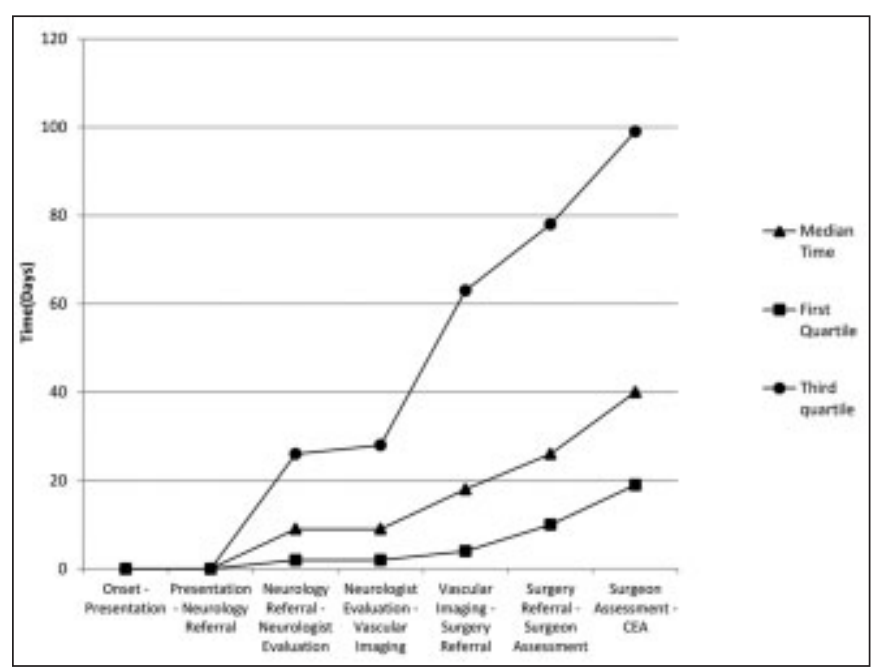

Figure 3: Accumulated time model for time intervals between clinical milestones. Each point represents the accumulated time if patient experienced median, first quartile, or third quartile time intervals between each clinical event.

This indicates that education for primary care providers on the need for prompt referral for surgical consideration, as well as the need to streamline provision of imaging in possible surgical candidates, are paramount in reducing systemic delays. However, these would not address some of the greatest increased time intervals in our analysis, as no reasons for the delay between receipt of referral by neurology and by vascular surgery were identified in patient records. It may be that a streamlined referral process with a clear identification of patient acuity, as well as results from urgently obtained vascular imaging, will help neurologists and vascular surgeons triage appropriate patients for rapid assessment, ideally with multidisciplinary cooperation designed to foster rapid surgical intervention when needed. This may require systematic development of more rapid referral systems and for stroke prevention clinics to create greater capabilities to see patients with symptomatic carotid disease in a timely fashion.

In this cohort, there was minimal time between symptom onset and presentation to medical care, and between presentation and initial referral to neurology. This suggests awareness on the part of patients and primary care physicians on the need for rapid referral, although specific instances of delays in these stages were observed. However, increased time intervals began accruing after patients were referred to neurology. Although there was minimal time between neurologist assessment and vascular imaging, some of this is due to some patients having imaging completed prior to neurology assessment. Further time was accrued once imaging was completed, with increased time intervals between this point and referral to surgery in patients without previously completed imaging. Time was also accrued between referral to a surgeon and surgical assessment, and between surgical assessment and CEA. In many cases, delays may be unavoidable; in two-thirds of delays with documented reasons, medical complications or uncertainty regarding symptoms were cited as the cause. However, this was not the 
case in all patients. Several delays occurred due to delays in obtaining vascular imaging, or in delayed referrals by primary care physicians. These delays could be reduced or eliminated by streamlining or reorganizing various aspects of the referral process; for instance, rapid triage of vascular imaging in appropriate patients, or in organizing education regarding referral processes for primary care physicians. The time points identified in this should be targeted for systematic review and specific interventions where appropriate in order to identify other ways to improve urgent referral systems for neurologists and vascular surgeons.

Our study complements work by others in identifying reasons for delay in CEA. Outpatient referrals, living farther from the hospital, and retinal symptoms were associated with longer times to $\mathrm{CEA}^{14}$. Our study did not find clear associations between these factors and delay to CEA, although the small numbers in our cohort may have been insufficient to determine the strength of such an association. In our population, there were no recurrent strokes or ischemic events prior to endarterctomy, but delays to CEA are associated with a higher risk of preoperative stroke, many of which can be disabling or fatal ${ }^{9}$. These must be balanced against the risk of stroke associated with too-early intervention, as CEA within two days of the event has been associated with a higher risk of stroke than CEA performed between 3-14 days ${ }^{16,17}$. The risk of early intervention must be further balanced against the risk of recurrent strokes, particularly in neurologically unstable patients ${ }^{18}$. Nevertheless, in addressing the areas of greatest delay, those developing stroke prevention systems for patients with symptomatic carotid disease may consider these factors while trying to reduce delays between receipt of patient referral and assessment by neurologists or vascular surgeons.

There are several important limitations to this study. First, this is a small sample from a single tertiary centre, so the generalizability of these results may be limited. Our centre's referral process may not reflect those at other institutions, though we believe our system may actually have shorter delays than other centres without a single triage list or a stroke prevention clinic process. Further research in other centres would be needed to confirm this. There also may be sampling error as the most common reasons for delay were shared only by a small number of patients. Our study does not capture those patients who were operated on by neurosurgeons or underwent carotid stenting by interventional neuroradiology; these cases comprise less than $10 \%$ of the revascularization procedures at our institution, but it may be that delays in these cases may have occurred at different times, or been due to different reasons, than the cases we captured in our analysis. Our cohort does not include patients who were referred to neurology while already admitted to vascular surgery, which may reduce the number of inpatients included in our analysis. In addition, less than half of the patients with delayed CEA had reasons for the delay documented; it may be that other reasons existed for the remainder of the group and that these would be more important or common. In order to further determine the reasons for delay to carotid endarterectomy in symptomatic patients, all institutions should ensure that processes are in place to identify delays in referral, evaluation and surgery, and to determine and record the reasons for these delays where they occur. Researchers should also try to identify delays and their reasons in a broader sample of institutions in order to ensure the validity of these findings and to identify both local and general strategies for the elimination of these delays. However, our data suggest opportunities to improve timely access to CEA in patients with symptomatic carotid artery stenosis. Refinement of referral systems is needed in order to ensure that patients with symptomatic carotid disease receive the appropriate therapy within the recommended guidelines.

\section{REFERENCES}

1. Giles MF, Rothwell PM. Risk of stroke after early transient ischemic attack: a systematic review and meta-analysis. Lancet Neurol. 2007;6(12):1063-72.

2. Rothwell PM. Prediction and prevention of stroke in patients with symptomatic carotid stenosis: the high-risk period and the highrisk patient. Eur J Vasc Endovasc Surg. 2008;35(3):255-63.

3. Eliaszew M, Kennedy J, Hill MD, Buchan AM, Barnett HJ, North American Symptonmatic Carotid Endartrectomy Trial Group. Early risk of stroke after a transient ischemic attack in patients with internal carotid artery disease. CMAJ. 2004;170(7):1105-9.

4. North American Symptomatic Carotid Endarterectomy Trial Collaborators. Beneficial effect of carotid endarterectomy in symptomatic patients with high-grade carotid stenosis. New Eng J Med. 1991;325(7):445-3.

5. Rothwell PM, Eliaszw M, Gutnikov SA, Warlow CP, Barnett HJ. Endarterectomy for symptomatic carotid stenosis in relation to clinical subgroups and timing of surgery. Lancet. 2004;363 (9413):915-24.

6. Furie KL, Kasner SL, Adams RJ, et al. Guidelines for the prevention of stroke in patients with stroke or transient ischemic attack. Stroke. 2011;42(1):227-76.

7. Gladstone DJ, Oh J, Fang J, et al. Urgency of carotid endarterectomy for secondary stroke prevention: results from the registry of the Canadian Stroke Network. Stroke. 2009;40(8): 2776-82.

8. Ballotta E, Menegehetti G, Da Giau G, Manara R, Saladini M, Baracchini C. Carotid endarterectomy within 2 weeks of minor stroke: a prospective study. J Vasc Surg. 2008;48(3):595-600.

9. Andgren S, Sjöberg L, Norvving B, Lindgren A. Time delay between symptom and surgery in patients with carotid artery stenosis. Acta Neurol Scand. 2011;124(5):329-33.

10. Johannson EP, Wester P. Delay from symptoms to carotid endarterectomy. J Intern Med. 2008;263(4):404-11.

11. Vikatmaa P, Sairanen T, Lindholm JM, Capraro L, Lepantalo M, Veremo M. Structure of delay in carotid surgery - an observational study. Eur J Endovasc Surg. 2011;42(3):273-9.

12. Fairhead JF, Mehta Z, Rothwell PM. Population-based study of delays in carotid imaging and surgery and the risk of recurrent stroke. Neurology. 2005;65(3):371-5.

13. Khashram M, Roake JA, Lewis DR. Patient flow to carotid endarterectomy: hastening the patient journey. ANZ J Surg. 2010;80(6):406-10.

14. Jetty P, Husereau D, Kubelik D, et al. Wait times among patients with symptomatic carotid artery stenosis requiring carotid endarterectomy for stroke prevention. J Vasc Surg. 2012;56(3): 661-7.

15. Purkayastha D, Grant SW, Smyth JV, McCollum CN. Delayed carotid surgery: what are the causes in the north west of England? Eur J Vasc Endovasc Surg. 2012;43(6):637-41.

16. Bond R, Rerkasem K, Rothwell PM. Systematic review of the risks of carotid endarterectomy in relation to the clinical indication for and timing of surgery. Stroke. 2003;34(9):2290-301.

17. Strömberg S, Gelin J, Österberg T, Bergström GML, Karlström L, Österberg K. Very urgent carotid endarterectomy confers increased procedural risk. Stroke. 2012;43(5):1331-5.

18. Cappocia L, Sbarigia E, Speziale F, Toni D, Fiorani P. Urgent carotid endarterectomy to prevent recurrence and improve neurologic outcome in mild-to-moderate acute neurologic events. J Vasc Surg. 2011;53:622-8. 